on both occasions. There are numerous reports of recurrences after curettage.

The main controversy concerns aetiology. Jaffe and Lichtenstein ${ }^{1-6}$ both believe that it is a benign tumour of osteoblastic connective tissue derivation. The main arguments against this are the recording of a recurrence after complete excision, the self-limiting nature of the size of the nidus irrespective of its duration, and the intense formation of a perifocal zone of sclerosis.

Lindbom et al. ${ }^{7}$ described a characteristic angiographic appearance of a small vessel with an irregular lumen supplying a highly vascular area of bone, with an intense circumscribed blush appearing early in the arterial phase and persisting late into the venous phase. The appearance has recently been confirmed $^{8}$ and may well be a useful diagnostic test. This finding, together with the vascularity of the nidus, the prominent vascularity of the adjacent soft tissue, and prolonged symptomatology in the absence of definitive radiological changes, suggest a developmental relationship between the nidus and the associated vascular changes. Whether the vascular alterations represent cause or effect is not yet clear.

A vascular origin might also help to explain the intense pain. No abnormal neurogenic tissue or glomus cell hypertrophy has ever been found. Could the pain be due to a large blood supply confined to a small area within rigid walls?

1 Jaffe, H. L., Archives of Surgery, 1935, 31, 709.

2 Sim, F. H., Dahlin, D. C., and Beabout, J. W., fournal of Bone and foint Surgery, 1975, 57A, 154.

3 Worland, R. L., Ryder, C. T., and Johnston, A. D., fournal of Bone and foint Surgery, 1975, 57A, 277.

4 Jaffe, H. L., and Lichtenstein, L., Fournal of Bone and foint Surgery, 1940, $22,645$.

5 Jaffe, H. L., Tumors and Tumorous Conditions of Bones and Foints. p. 92. Philadelphia, Lea and Febiger, 1964.

- Lichtenstein, L., Bone Tumors, 3rd. edn., p. 90. St. Louis, Mosby, 1965.

7 Lindbom, A., et al., Acta Radiologica, 1960, 54, 327.

8 O'Hara, J. P., et al., fournal of Bone and foint Surgery, 1975, 57A, 163.

\section{Dangers in Radiology?}

Many professional societies have good records of membership covering long periods, and these are potentially valuable resources for research into the occupational hazards faced by their members. One of the best known examples is within our own profession, where study of the causes of deaths of radiologists has contributed substantially to knowledge of the hazards of radiation. The excess risk of leukaemia in U.S. radiologists had been reported several times before Warren in $1956^{1}$ claimed that radiologists also experienced an additional, non-specific shortening of life, not manifest as any one disease. At about the same time, however, Court Brown and Doll ${ }^{2}$ found no excess risk of leukaemia or of general mortality in British radiologists, and Seltser and Sartwell ${ }^{3}$ criticized Warren's conclusions on statistical grounds.

The possibility of a non-specific shortening of life has now been raised again. Matanoski, Seltser, Sartwell, and others ${ }^{4}$ have looked at mortality in U.S. radiologists up to 1969 and compared their experience with that of their contemporaries who were physicians, ophthalmologists, and otolaryngologists. ${ }^{5}$ Among those joining their respective colleges in 1920-9, and again in those joining in 1930-9, the radiologists had the highest mortality from both cancer and from all other causes. But among those joining in 1940-9 the radiologists, while still having the highest mortality from cancer, had the lowest mortality from all other causes.

Two phenomena are given particular attention in the report. Firstly, the high leukaemia mortality in the first two groups of radiologists was not found in those joining in 1940-9; on the other hand, while the incidence of lymphoma was not increased in radiologists who joined in 1920-9, it was increased in those who joined later. Several possible interpretations, including damage to the immune response, are offered for this. Secondly, why should the early radiologists have had the highest death rates from diabetes, cardiovascular-renal disease, stroke, hypertension, and suicide?

Unfortunately the authors have chosen the wrong denominators for their statistical testing. This is unlikely to have invalidated their findings on mortality from individual diseases, but may mean that the "non-specific shortening of life" is merely variation within limits that may be ascribed to chance. Furthermore, as they themselves say, at least five and perhaps 20 further years' follow-up on the 1940-9 cohort will be needed to confirm some of the trends described. Until this is done, there seems no reason to change our 1958 belief $^{2}$ that the case has not been proved.

1 Warren, S., Fournal of the American Medical Association, 1956, 162, 464.

2 Brown, W. M. C., and Doll, R., British Medical fournal, 1958, 2, 181.

3 Seltser, R., and Sartwell, P. E., Fournal of the American Medical Association, 1958, 166, 585.

4 Matanoski, G. M., et al., American fournal of Epidemiology, 1975, 101, 188.

5 Matanoski, G. M., et al., American Fournal of Epidemiology, 1975, 101, 199.

\section{Bacteraemia from the Bowel}

The study of transient bacteraemia following therapeutic trauma is founded on two classical examples. That produced by instrumentation in the lower urinary tract was first fully described by Barrington and Wright, ${ }^{1}$ in whose paper the page heading (though not the title) is "Catheter Fever," the term formerly applied to the clinical manifestation before its nature was known. Five years later Okell and Elliott ${ }^{2}$ established the existence of bacteraemia after dental extraction and the factors governing its frequency. Later studies have extended these observations. Indeed the variety of occurrences and manipulations in the mouth said to be capable of releasing bacteria into the blood is surprising. Nevertheless any trauma which exposes severed or torn vessels in a lumen heavily laden with bacteria is liable to have this result, and this means most of the alimentary tract and any infected urinary tract.

By far the most heavily bacteria-laden area of the whole body is the lower bowel. It would be surprising if a few of its myriad inhabitants did not pass through the mucosa. In fact there is evidence that they do in the normal bowel, to be arrested in mesenteric lymph nodes if in the lymphatics or by Kupffer cells in the liver if they enter the portal system. Surgical operation in such an area presents an obvious risk, and septicaemia has been recorded as following biopsy of a rectal polyp ${ }^{3}$ and peroral biopsy of the jejunal mucosa. ${ }^{4}$ These infections were due to a Klebsiella and Esherichia coli respectively, the latter in a patient whose jejunum was known to be abnormally colonized by enterobacteria. But several less easily explicable examples of bacteraemia of intestinal origin have recently been reported by Le Frock, ${ }^{5}$ of West Virginia Uni- 